\title{
MIRADA REFLEXIVA DE LAS MINAS ANTIPERSONAL (MAP); MUNICIONES SIN EXPLOTAR (MUSE) Y ARTEFACTOS EXPLOSIVOS IMPROVISADOS (AEI) EN COLOMBIA. ACERCAMIENTO DESDE EL ANÁLISIS DE CASO*. \\ REFLECTIVE VIEW OF THE ANTIPERSONNEL MINE, (APM). UNEXPLODED AMMUNITIONS (UA) AND IMPROVISED EXPLOSIVE ARTIFACTS (IEA) IN COLOMBIA. \\ APPROACH FROM THE CASE ANALYSIS.
}

\section{CRISTIAN CAMILO OVIEDO MONROY*}

\section{R E S U M E N}

El presente escrito aborda la problemática de las minas antipersonal en Colombia. Para ello se hace un recorrido de lo dicho a través de fuentes oficiales y se abordan datos, porcentajes, tablas, documentos y acuerdos, visualizando el estado en el que se encuentra tal fenómeno en el llamado postconflicto. En un segundo momento y contrastando información oficial con lo real; se hace un encuentro oral con un afectado de mina antipersonal (MAP), cuya finalidad fue dar voz a una de las centenares de historias no emergidas que ha dejado la guerra en el país. En este sentido, se apuesta a un dialogo disciplinar donde la sociología apoyada en la antropología se acerca a una historia particular del conflicto. Asimismo y propiciando el ejercicio teórico se intenta debatir la violencia cultural como presunta forma de vida, en tanto su naturalización en la cotidianidad nacional.

PALABRAS CLAVE: Colombia, Mina Antipersonal (MAP), Artefacto Explosivo Improvisado (AEI), Munición sin Explotar (MUSE), convención, violencia cultural.

\section{A B S T R A C T}

This paper addresses the problem of antipersonnel mines in Colombia, because of that, it takes a tour of what has been said through official sources, it broaches: data, percentages, tables, documents and agreements, visualizing the state in which such problems are found in the so-called postconflict. In a second moment by contrasting official with the real information an oral encounter is made with an affected antipersonnel mine (MAP), whose goal was to give voice to one of the hundreds of not emerged stories that the war has left in the country. In this sense, it is committed to a disciplinary dialogue where sociology supported by anthropology approaches a particular history of the conflict. It also encourages the theoretical exercise is about cultural violence as the way of life, being naturalized in the national every day.

KEYWORDS: Colombia, Antipersonnel Mine (APM), Improvised explosive Artifacts (IEA), Unexploded Ammunitions (UA), convention, cultural violence.

\footnotetext{
* Este artículo es un primer esfuerzo para recabar algunos de los documentos oficiales de lo dicho respecto a minas antipersonal; además de la apuesta relacional con la historia oral de un afectado directo por MAP. Así pues, se encamina a un ejercicio reflexivo sociológico apoyado de la antropología.

** Sociólogo de la Universidad del Tolima. Adscrito a la Facultad de Ciencias Humanas y Artes. Cl. 42 \#1b-1, Villeta, Ibagué, Tolima. Código Postal: 73001, Ibagué, Colombia. Correo electrónico: kmilooviedo90@gmail.com
} 
A Ramiro: por su esfuerzo y valor; quien por circunstancia socioeconómica como cientos de jóvenes, se vio obligado, con temores enmascarados de coraje a luchar por una guerra que no le pertenecía...

\section{INTRODUCCIÓN}

El conflicto entre los llamados grupos armados al margen de la ley (GAML) y fuerza pública en Colombia es un fenómeno al parecer por antonomasia, cultural, hostil-histórico, degradante y profundamente costoso que directa $\mathrm{o}$ indirectamente pareciera determinar el carácter identitario del ser Colombiano ya que afecta al individuo, a la familia y/o a la comunidad. Dentro de las diversificadas formas y estrategias de confrontación que se han implementado para atacar-deteriorar al enemigo en este ambiente de guerra los más usuales han sido las Minas antipersonal (MAP) y artefactos explosivos improvisados (AEI). (Vicepresidencia República de Colombia 2008). Los tratados humanitarios internacionales mencionan la utilización de estos artefactos como una "clara violación a los Derechos Humanos (DD.HH.), al Derecho Internacional Humanitario (DIH) y a la legislación Nacional e internacional en la materia” (op., cit., p. 16). Si bien el hecho prohibitorio de dichos artefactos no redujo su utilización, el efecto contrario posicionó a Colombia por tradición como "la tierra del MAP", debido a que las evidencias del manejo de artefactos explosivos como los mencionados aumentaron considerablemente en los últimos años.

Así las cosas, la táctica hostil de las minas antipersonal (enemigo oculto) se consideró indigno, ya que dentro de los métodos y técnicas de guerra, el Derecho Internacional Humanitario (DIH) no concibe que las Naciones hagan uso ilimitado de artefactos bélicos, de ahí que, las prácticas dónde se utilizaran minas antipersonal fueran restringidas, puesto que tales instrumentos no reconocen entre combatientes de guerra, civiles adultos o niños. En países como Colombia, surtió un efecto tan eficiente para quienes lo utilizaban, -aumento de bajas e incapacidades a fuerza enemiga-, que tales artefactos empezaron a ser cada vez más manipulados. El hecho resultó tan alarmante, y el número de víctimas tan amplio, que terminó saliéndose de control para la fuerza pública, con fines de ilustración según cifras oficiales desde 1990 hasta agosto de 2008 de la Vicepresidencia República de Colombia y el programa de acción integral contra minas antipersonal (2008) se reportaron: "7.204 colombianos víctimas de minas antipersonal (MAP), municiones sin explotar (MUSE) y artefactos explosivos improvisados (AEI); en el 46\% de los municipios se ha registrado al menos 
una víctima, y en $61,8 \%$ se ha evidenciado algún grado de contaminación" (p. 3, 4). De acuerdo con el informe más reciente de victimas de minas antipersonal, de 1990 a la fecha de corte, es decir, 31 de octubre de 2017, "se han registrado 11.513 víctimas por minas antipersonal y munición sin explosionar, siendo el 2006 el año más crítico, pues se presentaron 1.232 víctimas, el mayor número en toda la historia de Colombia" (Dirección para la acción integral contra minas antipersonal. Descontamina Colombia, 2017, párr. 8). Igualmente, se revela que en lo corrido de 2017, se han presentado 39 víctimas en 15 municipios de 9 departamentos del país. Aunque la perdida de vida es muy preocupante, no resta importancia quienes logran sobrevivir a los accidentes; siendo las incapacidades con daños físicos y psicológicos los causantes de perjuicios mayores.

Esta problemática ha dejado heridas al $80 \%$ (9.237) de las víctimas y 2.276 personas han fallecido a causa del accidente, es decir, 1 de cada 5 víctimas muere. Por otra parte, Colombia ha sido uno de los países del mundo con mayor cantidad de víctimas de la fuerza pública y esto ha significado que del total de víctimas, el $61 \%$ han sido miembros de la fuerza pública y el $39 \%$ restante, corresponde a civiles. (Dirección para la acción integral contra minas antipersonal. Descontamina Colombia, 2017, párr.9).

A lo anterior se suma que un porcentaje de afectados son niños, mujeres y hombres de origen campesino; la mayoría (86 \%) de las víctimas han sido personas mayores de edad de sexo masculino (9.951), una gran parte de estas víctimas pertenecen a la fuerza pública. Si bien, al solo tener en cuenta las víctimas civiles, el grupo demográfico más afectado, de nuevo, son las personas adultas de sexo masculino (65\%); el segundo grupo que muestra una significativa afectación son los hombres menores de edad (20 \%) y luego están las personas mayores de edad del sexo femenino y las menores de edad del sexo femenino con el $8 \%$ y $6 \%$, respectivamente (Dirección para la acción integral contra minas antipersonal. Descontamina Colombia, 2017)

Aunque las cifras oficiales mostraron incongruencias con el número concreto de víctimas en lo relacionado al periodo 1990-2008, la Politica nacional de acciòn integral contra minas antipersonal (2008) menciona que "desde 1990 hasta agosto de 2008 se tiene registrado un total de 7.204 colombianos víctimas de minas antipersonal 
(MAP)" (p. 3). Mientras que en el documento Conpes 3567 (2009) se menciona que el número de víctimas no es de 7.204 sino de "7.451 víctimas de minas antipersonal, 4.016 accidentes y 9.520 incidentes que hacen suponer peligros relacionados con la existencia y/o sospecha de presencia de estos artefactos" (p. 21). Más que contradicciones entre las mismas cifras oficiales, la realidad inexcusable estaría en las personas que no se comprometieron con la lucha armada, aunque sí, la afrontaron y la hicieron parte de su cotidianidad.

A partir de lo planteado, se busca una aproximación y posteriores reflexiones a lo que se creería un fenómeno culturalizado producto de escenarios hostiles. Para ello se recurre a fuentes oficiales: datos, porcentajes, acuerdos y consensos normativos, que se han encaminado a la resolución de dicha problemática, la que se ha tornado en el devenir de los años como incontrolable y compleja. En este orden, un primer momento de búsqueda de lo escrito, son los recursos o instrumentos para comprender a partir de lo dicho, el estado de socialización de tal problemática y los avances que dice tener. En segundo orden, aunque no de menor importancia, para enriquecer el abordaje del tema, se inicia la búsqueda de una mirada menos estadística del fenómeno en discusión, por ello la importancia de un actor directo del conflicto. Por tanto, se toma distancia de los datos porcentuales y se da voz a quien las historias oficiales no le permiten, ya que se considera imprescindible el acercamiento a dicha situación compleja desde la perspectiva de quien la vivenció realmente, apostándole a validar el desarrollo oral y estudio de caso desde un afectado directo. Para estos efectos, se hizo uso de nombres ficticios a fin de preservar la intimidad e identidad de quien contribuyó con el propósito de reconstruir una historia tradicional de guerra. Así pues, vista la fuente oral tanto enriquecedora como correctora de sucesos, se propone una mirada alterna y real del ser víctima de las minas antipersonal en Colombia. Para este segmento, se reviven sucesos reales en tiempos de guerra, historia tal que sólo está clara en la mente de quien la soportó. Jóvenes, -en parteque desconociendo procesos políticos o por la constante escasez económica, no tuvieron otra opción que hacer parte de una guerra que no entendían, entendían mal o no les interesaba. Es así, como esta memoria individual como método, permite abarcar elementos de la tradición oral que en ellos quedaron.

En este sentido, la inclusión de lo oral, reconstrucción de la memoria como herramienta, representa esa forma de 
recurrir a hechos reales sin perder de vista la importancia de los documentos oficiales abordados y el enriquecedor contraste. La apuesta es entonces a la mirada reivindicativa de la historia no oficial, esa historia abandonada, pero que vivenciaron cientos de combatientes y campesinos en el furor y adrenalina de la guerra y el conflicto armado colombiano. Seguido, se revisa una de las varias propuestas sobre el concepto de cultura y la apuesta relacional con lo entendido por violencia cultural. Se reflexiona sobre las implicaciones de la hostilidad cultural en países como Colombia y los costos empobrecedores que ha conllevado la problemática aquí abordada.

Con el propósito de evitar sucesos de revictimización de las personas que vivieron hechos de guerra, se apunta a reflexionar acerca de las condiciones en las que se encuentran y lo que esto implica para ellos; se mira de forma sucinta la asistencia Estatal en reintegración socioeconómica y moral. Cabe resaltar la admirable decisión de los afectados, ya que coinciden en dejar de lado los sucesos traumáticos e intentar continuar con una vida normal, como la que llevaban hasta antes del accidente. Ahora, en lo que respecta a las minas antipersonal en el país, paradójicamente sólo hasta cuando el Estado Colombiano entra a ser parte del Convenio Internacional de Ottawa Canadá (1997), pareció tener la obligatoriedad y vital importancia la reducción de campos contaminados y la reparación a la población afectada por minas antipersonal.

\section{CARACTERIZACIÓN DE UN PROBLEMA BÉLICO: MINA ANTIPERSONAL (MAP), MUNICIÓN SIN EXPLOTAR (MUSE), AR- TEFACTO EXPLOSIVO IM- PROVISADO (AEI)}

\section{1. Contexto sociocultural.}

Si bien Colombia es uno de los mayores consumidores y productores de MAP en años recientes, no se le puede acuñar como el creador responsable de tan perjudiciales artefactos utilizados para encuentros bélicos. La utilización de estos explosivos se remontan a épocas de la I Guerra Mundial, según Unicef (2000), es así como de Fowler (1992), menciona que "soldados alemanes enterraban casquetes de artillería rellenos de pólvora o dinamita con un detonador a ras de tierra para detener el avance de tanques franceses y británicos" (p. 7). Lo anterior, hizo que dichas minas fueran detectadas con facilidad por el enemigo, obligando a la creación de artefactos más pequeños, constituyéndose la instauración de minas antipersonal, cuya 
principal característica fue ser casi indetectables para la fuerza enemiga, esto sin soslayar la protección de las minas antitanque ${ }^{1}$ (artefactos más grandes y visibles). Así las cosas, en el transcurrir de los años, diferentes países en varias regiones del mundo han utilizado estos implementos explosivos para sacar provecho de las guerras en las que se han involucrado.

Con gran preocupación por la violación de la dignidad humana, que cada vez suma más víctimas a nivel mundial, se negocia la convención sobre la prohibición del empleo, almacenamiento, producción y transferencia de minas antipersonal y sobre su destrucción conocida como la Convención de Ottawa de 1997, que fue la causa para que más de cien Naciones determinaran poner fin a los daños causados por minas antipersonal. La Convención se abrió para la firma de todos los Estados desde el 3 de diciembre (1997) hasta el 4 de diciembre (1997) en Ottawa Canadá y posteriormente permaneció abierta en la sede de las Naciones Unidas en New York hasta que entró en vigor (Paradójicamente, el país sede fue uno de los pocos países junto a Rusia que se negaron a firmar la aprobación de prohibición e inicio de desminado en sus Naciones).

\footnotetext{
El comité internacional de la cruz Roja, menciona que las minas antitanque contienen entre 2 kilogramos y 9 kilogramos de explosivo. (Comité Internacional de la Cruz Roja, 1998)
}

Así pues, observando que las (MAP) en Colombia se han utilizado en diversas regiones del país, se comprende según el programa acción integral contra minas antipersonal en Colombia (PAICMA) ${ }^{2}$ (2014), (basado en el IMAS ${ }^{3}$ ) que las MAP son el "artefacto que explota por la presencia, cercanía o contacto de una persona y puede incapacitar, lesionar o matar a una o más personas. Las minas antipersonal de fabricación artesanal son conocidas como Artefactos Explosivos Improvisados (AEI)" (p. 35). De hecho, una problemática a enfrentar por el país en épocas de posconflicto, es la cantidad de artefactos de guerra utilizados y que nunca se detonaron pero que son una amenaza directa, la llamada munición sin explotar (MUSE) es decir, un "artefacto explosivo que ha sido cargado, su fusible colocado, armado o por el contrario preparado para su uso o ya utilizado. Puede haber sido disparado, arrojado, lanzado o proyectado pero que permanece sin explotar por cualquier razón" (p. 35). Esta problemática agudiza la contaminación de los terrenos rurales colombianos y zonas de actividad económica campesina, siendo ellos involucrados y afectados directos de esta tradición cultural hostil. Para contrarrestar tal

\footnotetext{
${ }^{2}$ Actual Dirección para la Acción Integral contra Minas Antipersonal (DAICMA)

${ }^{3}$ Por sus siglas en ingles International Mine Action Standars.
} 
inconveniente, que afecta la sostenibilidad económica de los campesinos y que se relaciona directamente con los lugares donde se encuentran enterrados la diversificación de estos artefactos, el Gobierno ha apostado a las relaciones interinstitucionales para lograr campos intervenidos y posteriormente descontaminados.

De lo antes abordado se podría decir que no se anula la posibilidad que este conjunto de actos sea un legado cultural empobrecedor que afecta también a los civiles de idiosincrasia campesina; aunque infundir terror es un método tradicional de los grupos armados, el amedrentamiento por los campos minados genera el desplazamiento de personas y comunidades, convirtiendo a civiles en víctimas directas; la ley 1448 de 2011, Art. 3 (Congreso de la Republica, 2011) considera victimas a aquellas personas "que individual o colectivamente hayan sufrido un daño por hechos ocurridos a partir del $1^{\circ}$ de enero de 1985 , como consecuencia de infracciones al Derecho Internacional Humanitario o de violaciones graves y manifiestas a las normas internacionales de Derechos Humanos" (p.1). Al campesino o mujer laboriosa le aterra que, dentro de sus actividades cotidianas vaya a sus trabajos de cultivo y se encuentre una mina sembrada. Parte de este temor se da por experiencias de muertes de conocidos/cercanos o familiares, causando mayor conmoción a personas que ejercen actividades económicas agrícolas, razón por la que concluyen abandonar parcelas.

Por otra parte, es importante resaltar que son sucesos de guerra con costos de vida y económicos muy altos para la Nación, tanto así que se recurre a la solicitud de ayuda internacional para dar marcha a proyectos como los de acción integral contra las minas, en la medida que hablar de una Colombia desminada (como frase bonita) no estaría en la posibilidad real sólo con un presupuesto Nacional. De hecho lo establecido en el Conpes 3567 aclara el PAICMA (procuraduría delegada para la prevención en materia de derechos humanos y asuntos étnicos grupo de justicia transicional, 2011) que para el 2011 se estimó un presupuesto de " $\$ 105.647$ millones de pesos para el cuatrienio de 2009-2012, de los cuales se esperaba recibir un $24 \%$ de la cooperación internacional y el $76 \%$ restante de las partidas presupuestales asignadas por el Ministerio de Defensa Nacional y el mismo PAICMA" (p. 11). De ahí la afanosa necesidad de buscar vínculos externos, dar a conocer tal problemática y posterior solicitud de apoyo en recurso económico o humano. 
Por otra parte, las personas victimas de eventos violentos, como lo es un ataque con elementos explosivos coinciden en lo doloroso que resulta continuar, sobre todo por la falta de estabilidad económica; sobrevivir no es tranquilidad promisoria ni garantía de óptima recuperación, debido a las inconsistencias con los procesos de asistencia/apoyo psicológico y socioeconómico. A esto se suma el abrupto cambio de vida de las personas y la interrupción de labores de actividad económica cotidiana ligado directamente con los proyectos de vida, en tanto que, los sobrevivientes -en caso de ser civiles-, no pueden resolver o resuelven con desconsuelo la forma de seguir subsistiendo autónomamente (aquí la llamada sensación de abandono Estatal), de hecho, las personas afectadas, generalmente provienen de estratos socioeconómicos 1 y 2 y se ven la dispendiosa necesidad de recurrir a las asistencias médicas del Estado para lograr salir de los sucesos traumáticos que ha dejado el accidente. Según Unicef (200o), de acuerdo con la organización Physicians for Human Rights, PHR los costos médicos para una idónea recuperación "oscilan entre los US\$3.00o y US\$5.00o, mientras que los costos de los aparatos para movilización que necesitarán un niño o niña víctimas de mina se encuentran por encima de los
US\$3.00o” (p. 9). Cabe aclarar que, la atención a hombres de fuerzas estatales accidentados en combate por MAP, cuentan con atención diferencial, es decir, existe mayor cobertura de desplazamiento y atención. Esto en parte se debe a la notable inversión porcentual del producto interno bruto (PIB) nacional a los ejércitos regulares de combate y lo relacionado a su asistencia, seguridad e inteligencia. Por ejemplo, dentro de las formas de evacuación para hombres de la fuerza pública caídos en combate, el más usual es el aéreo, en su trayecto, los aquejados cuentan con asistencia médica de urgencia, asistidos por profesionales del tema hasta su llegada a clínica especializada; mientras que para los campesinos, a los que su cobertura de acceso/salida rural es limitada (carreteras de difícil paso, vivienda rural distante) las evacuaciones se tornan recursivas en transportes como: motocicletas, carros y bestias (caballos y mulas). Se debe mencionar el sumo cuidado que se requiere (según médicos especialistas) para evacuar y atender personas heridas a causa de las minas antipersonal, siendo su mayor riesgo morir desangrados, con hemorragias y otros daños causados por la explosión. Como establece el Conpes (2009) "las víctimas enfrentan altos costos para acceder a los procesos de reclamación y goce de 
beneficios puesto que "los procesos de reconocimiento y pago de reclamaciones son dispendiosos y prolongados" (p. 39) lo cual se resalta como una de las falencias más relevantes evidenciado en tal política pública debido a la ausencia de garantías para los costos de traslado, alojamiento y manutención. Es por ello que se enfatiza ésta, como una problemática sin control.

\section{2. Situación de las MAP Y AEI en Colombia y la Violencia Cultu- ral.}

Las minas antipersonal en Colombia han sido un problema creciente, cultural y hasta identitario pues cualquier colombiano podría hablar o hacer parte del dolor que esto implica. Aunque se han sumado esfuerzos nacionales e internacionales para contrarrestar dicha complicación, la incertidumbre crece al no conocerse con exactitud los territorios contaminados con minas, ya sea por siembras recientes o de años anteriores. Según la Convención de Ottawa. Artículo $5^{\circ}$ se recalca la importancia de la destrucción de minas en los territorios, a lo que se agrega que:

Cada Estado parte se compromete a destruir, o a asegurar la destrucción de todas las minas antipersonal colocadas en las zo- nas minadas que estén bajo su jurisdicción o control, lo antes posible, y a más tardar en un plazo de 10 años, a partir de la entrada en vigor de esta Convención para ese Estado Parte. (PAICMA, 2014, p. 9)

Cuando Colombia decide hacer parte del convenio internacional, entra en un gran reto, cuya mayor obligación es tener un conocimiento detallado y en profundidad de zonas contaminadas con minas antipersonal (sin lograrlo), para poder cumplir con tal compromiso, fue necesario la unión intersectorial y las gestiones políticas para la ejecución de la Acción Integral contra Minas Antipersonal (AICMA) del periodo 2009-2019, de acuerdo con "los compromisos adquiridos por el Estado colombiano con la ratificación de la Convención de Ottawa. En su desarrollo, se plantea la problemática de las minas antipersonal en Colombia y se describen las líneas estratégicas de corto, mediano y largo plazo" (p. 24). No obstante, existen hechos que han dificultado la pronta solución del problema del minado territorial, el más común es que las hostilidades no han cesado totalmente, a pesar que se han contrarrestado la utilización de las minas por un grupo armado (actos de desarme a grupos históricos como FARC-EP en 2017, otros grupos toman estas estrategias hostiles para 
continuar su ratificación, ocupar espacios de poder dejados por la guerrilla y evitar mostrar su debilidad antes las fuerzas estatales.

En la normatividad para el año 2014 se mostraron las mayores limitaciones por parte del Estado Colombiano en relación a las minas antipersonal, quienes admitieron la débil coordinación interinstitucional e interagencial de cara a la Acción integral contra minas antipersonal (AICMA), para empeorar, pareció sumarse una atención estatal escasa, ineficiente, agregándosele la corta utilización de los recursos de las entidades nacionales e internacionales donantes, por lo que, la crisis de aumento de víctimas mortales fue evidente, además de esto se considera que el daño humano físico, social y ecológico, está derivado en cuatro ejes problemáticos, según PAICMA (2014):

1) La débil coordinación interinstitucional e interagencial para responder, de forma oportuna, sostenible y con las intervenciones en marcha de la AICMA, a los problemas que afectan a las comunidades; (2) insuficiente capacidad institucional para contener la contaminación y desminar el territorio con MAP, MUSE y AEI; (3) deficiente gestión del riesgo por minas en términos de prevención y educación; y, (4) dificultades en el proceso de rehabilitación integral e inclusión socioeconómica de las víctimas de los accidentes por MAP. (PAICMA, 2014 p. 44)

De hecho, la consolidación y éxito de la AICMA está ligada al progreso en el fortalecimiento y recuperación de territorio, no es secreto que existe abandono estatal en diversas regiones del país, de ahí un plan de reconocimiento territorial; ha faltado un esquema que permita ver experiencias y avances de comunidades con problemas de minado que se han intervenido con anterioridad, en este sentido, si bien hay un avance con la existencia de comités por departamentos y regiones, ha persistido la ambigüedad en los resultados de cumplimiento de las propuestas sobre el nivel de participación de las comunidades.

Respecto a un costo financiero aproximado para el 2012 PAICMA (2014) hablaban que el proyecto contaba con un costo total "de $€ 7.200 .000$, que corresponden a $€ 6.000 .000$ de recursos donación y €1.200.00o de contrapartida nacional ( $€ 1.000 .000$ en efectivo y $€ 200.000$ en especie). El equivalente en moneda nacional de valor global del proyecto es de $\$$ 19.076.745.055". (Programa de Acción Integral Contra Minas Antipersonal (PAICMA) 2014, pp. 114-115). Con 
lo que no se cuenta hasta el momento, o por lo menos desde la mirada menos favorecida, ser víctimas de minas, es la violación al libre desarrollo de la personalidad y la estabilidad económica que se inflige a las personas afectadas. Aunque las respuestas estatales en los últimos años parecen mejorar, aun no es suficiente y con la falencia de no tomar en detalle las condiciones de los afectados. Como lo menciona Hernández (2003) respecto a dichas personas, "la vida de los afectados cambia drásticamente ya que deben transformar abruptamente la relación con su cuerpo, sus rutinas diarias, su sexualidad, sus sueños, su futuro" (p. 5). Prosiguiendo así con hechos traumáticos y retos que en su antigua cotidianidad un niño, hombre o mujer, le era apenas normal.

Dentro de las categorías dignas de vida en las que se esperaría pudiera vivir una persona en Colombia, se encuentra una serie de derechos que son violados (naturalizados) por sucesos con artefactos explosivos que son: el derecho a la vida, la integridad física y el bienestar socioeconómico, lo cual incluye: adecuada alimentación; medios para producir alimentos $o$ acceder a agua potable; nivel de vida adecuada para la salud mental y psicológica sin la presencia de miedo; acceso a la educación y las condiciones de trabajo favorables y seguras; adecuada vivienda y proceso de retorno seguro (en caso de desplazamiento forzado o refugiados); libertad de movimiento y libertad de asociación; participación política; acceso equitativo a servicios públicos y participación en la vida cultural y religiosas de las comunidades. A continuación, se expone el cuadro guía (ver cuadro 1) de acuerdo al documento Conpes 3667 (2009), en el que se menciona los derechos violados a personas víctimas de minas antipersonal en Colombia.

Como se evidencia en el esquema, son diversas las violaciones cometidas, siendo la más importante la del derecho a la vida, además de vulnerar derechos de no menor rango como la alimentación y los medios para producirla (en este caso los más afectados fueron los trabajadores de la tierra). Asimismo se evidencia la violación a la buena salud mental, que ha sido naturaliza de tal manera que existe una continua presencia de miedo, además de la negación de una vivienda digna a personas afectadas y limitaciones para acceder o continuar con nivel de formación educativa (especialmente los más jóvenes). Lo anterior muestra un deterioro psicosocial y en general un empobrecimiento del proyecto de vida de los afectados. 


\section{Cuadro 1. Desarrollo humano y derechos violados por MAP/ MUSE}

\begin{tabular}{|c|c|}
\hline $\begin{array}{c}\text { CATEGOPIAS DEL DESARPOLLO } \\
\text { HUMANO } \\
\text { (RANIS; ET ÁL. 2006; 6) }\end{array}$ & $\begin{array}{c}\text { DERECHOS VIOLADOS } \\
\text { POR LAPRESENCIA } \\
\text { Y/O SOSPECHAS DE CAMPOS } \\
\text { MINADOS (HORWOOD 2003; 942) }\end{array}$ \\
\hline 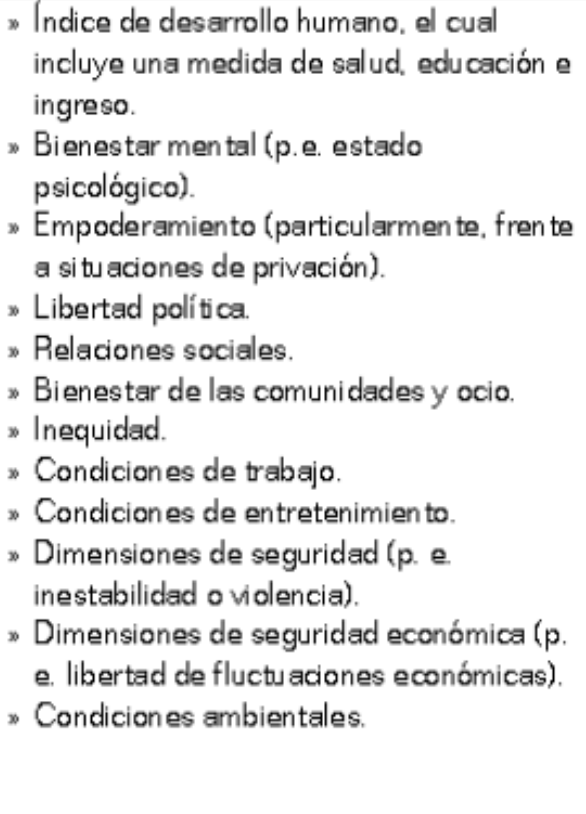 & $\begin{array}{l}\text { "Vida, in tegridad física y bienestar } \\
\text { socioeconómico en sentido amplio, lo cual } \\
\text { incluye las limitaciones o privación de: } \\
\text { „Adecuada alimentación, medios para } \\
\text { producir alimentos o acceder a agua } \\
\text { potable. } \\
\text { „ Nivel de vida adecu ado para la salud } \\
\text { men tal y psicológica sin la presencia de } \\
\text { miedo. } \\
\text { „Acceso a educación y condiciones de } \\
\text { trabajo favorables y seguras. } \\
\text { „Adecuada vivienda y procesos de retorno. } \\
\text { seguros (en caso de desplazamiento } \\
\text { forzado o refugiados). } \\
\text { „Libertad de movimien to y libertad de } \\
\text { asociación. } \\
\text { „Participación política. } \\
\text { „Acceso equitativo a senvicios públicos y } \\
\text { participación en la vida religiosay cultural } \\
\text { de las comunidades. }\end{array}$ \\
\hline
\end{tabular}

Fuente: Tomado de Programa de Acción

Integral Contra Minas Antipersonal (PAICMA 2014)

Cabe mencionar que, resarcir los derechos violados expuestos con antelación, por sospecha o presencia de minas a civiles campesinos y miembros de la fuerza pública, es orientado por el Derecho Internacional Humanitario (DIH); por lo que no es extraña la necesaria asistencia internacional con la llamada intervención humanitaria, de ello quedan ejemplos como el desminado humanitario o el desarrollo de familias guardabosques (iniciada en 2003) que a su vez fueron parte de la estrategia no tan prospera del llamado Plan Colombia -PC- de 1.999 que no evidenciaron los mejores resultados como se esperaban en los programas de gobierno de 2002-2010.
Así pues, apostando a la reflexión teórica es menester determinar el concepto de cultura en un ambiente hostil y la forma en que este puede configurar el aspecto identitario de los habitantes del territorio colombiano al desarrollar una forma de vida con violencia. Al respecto, Canclini (1981), va a mencionar el carácter polisémico del concepto, además procura ser crítico con la definición etnocentrista de cultura o cultivo de las razas civilizadas; aclara como el prejuicio europeo duró décadas estableciendo una dicotomía entre pueblos civilizados y barbaros, razón por la que se le acuña el antagonismo entre civilización y cultura. Ahora bien, tratando de dejar de 
lado la superioridad occidental del término, el autor concuerda con una definición antropológica de la cultura refiriéndose a la misma como:

Todo lo producido por todos los hombres lo que la naturaleza ha dado, sin importar el grado de complejidad y desarrollo alcanzado en relación con nuestras sociedades. Son parte de la cultura aún aquellas prácticas o creencias que suelen juzgarse manifestaciones de ignorancia (las supersticiones, los sacrificios humanos), las normas sociales y las técnicas simples de quienes viven desnudos en una selva, sujetos a los ritmos y los riesgos de la naturaleza (Canclini, 1981, p. 4)

Ésta definición de cultura cobijadora que pasó por varias miradas (debate académico) desde la antropología, la sociología y hasta la economía, mostró sin distinción de clase, que se podía entender por cultura también actos abominables, al tratarse de lo salido y producido por los seres humanos. De hecho, aduce que la visión occidental sin cultura- no fue fácil de desdibujar, ocasionando confrontaciones entre las academias europea y norteamericana por décadas. Aunque el término ha sido utilizado en diversos espacios, se puede decir que en el campo académico (donde se trabaja) es amplio y polisémico a causa de las diversas interpretaciones de acuerdo a su contexto.

La anterior y rápida contextualización de cultura, se hace sin distanciarla de la realidad colombiana, de allí el aterrizaje conciso de la posible violencia cultural en el país. Ahora, siendo el conflicto y sus vertientes un eje de importancia, se procede a aclarar lo entendido por violencia cultural, bajo el supuesto que es "cualquier aspecto de una cultura suceptible de ser utilizado para legitimar la violencia directa o estructural. La violencia simbolica incorporda a una cultura no mata o mutila como la violencia directa incorporada a la estructura" (Galtung, 2003, p.6). Aunque aquí la menciona como aquella que no mata directamente, es muy perniciosa y entendida como forma de vida dentro de la cultura de lo que que se podria inferir, una naturalizacion de la violencia. Hasta aquí, se hace una diferenciaciòn del concepto de cultura que el descrito por Canclini (1981), ya que para Galtung (2003) la violencia cultural incluye "aspectos de la cultura, el ámbito simbólico de nuestra existencia (materializado en religión e ideología, lengua y arte, ciencias empíricas y ciencias formales -lógicas, matemáticas), que puede utilizarse para justificar o legitimar violencia directa o estructura" (p.7). Citado autor, proporciona un 
buen ejemplo, cuando menciona el asesinato de personas, por la patria como "correcto", mientras que por un interés individual se determina "incorrecto". De lo anterior, de ser aplicable al contexto Nacional, demostraría un acto de crisis en el Estado y la democracia Colombiana, sumándose una demagogia caudillista del político, utilizando la persuasión de la masa, bajo el riesgo de intereses personalistas. Así pues, visto de esta manera la violencia de un artefacto explosivo no para allí, de ésta se manifiestan violencias simbólicas de no menor importancia para los afectados, tales como los casos de asilamiento social, visto por Goffman (1963) como falta de retroalimentación social, escases económica o laboral. La violencia cultural como inherente social determinaría pues un carácter de ser colombiano, del que cada uno lo expresaría de manera más profunda o superficial de acuerdo a la experiencia hostil vivida.

\section{SER VÍCTIMA EN CO- LOMBIA. ENCUENTRO ORAL CON AFECTADO DEL CONFLICTO. DE LO ATERRADOR A LO ESPE- RANZADOR.}

El trabajo de campo que sostiene esta parte del escrito, se desarrolló en periodos de 2015-2016 en el municipio del Líbano, de donde es oriundo Ramiro, un sobreviviente de mina antipersonal (MAP). Aunque la apacible tierra donde nació, no fue donde le arrebataron parte de su vida, si sucedió en territorios de Antioquia, hostil "tierra de MAP". Ramiro, como cientos de jóvenes, quien por dificultades socioeconómicas o problemática familiar, en el esplendor de su juventud (año 2003), no tuvo más salida que enlistarse a las filas del Ejército Nacional de Colombia. Lo inimaginable, probablemente para él, es que pocos años después de estar en servicio, como muchos otros jóvenes soldados; en zona selvática del bajo Cauca Antioqueño, bajo la tiniebla dolorosa $\mathrm{y}$ en compañía de un compañero ya muerto, se debatía entre la vida y la muerte, mientras esperaba el momento oportuno para poder ser evacuado del lugar donde pisó el artefacto explosivo y así lograr salvar su vida. En esta ocasión como en muchas otras, se reafirmaba la paradoja no oficial de, quien lucha en la guerra y quien se beneficia de ella, son actores sociales totalmente distantes y distintos.

La comida de perro como un menú obligatorio, las largas caminatas nocturnas, o el intento de descanso con un camuflado mojado al anochecer, fueron apenas unos de los recuerdos que 
Ramiro dejó emerger en aquellas conversaciones, aunque aquellos no serían los más gratos de su vida, -como lo afirmó- su fluidez no creó la necesidad de recurrir a preguntas específicas. De manera que, con el ánimo de validar el uso de la memoria individual como herramienta apreciable, los que permiten adicionar aspectos de la tradición oral; es éste, un intento de acercamiento oral desde la persona propiamente dicha; despojando cualquier interpretación, se permite aquí rescatar esas historias soterradas, dar voz al sujeto en sí y para sí. Como lo plantea Franco (2013) "Conocer y recrear las formas específicas de pensar y vivir en el mundo que la violencia implica adentrarse en lo local, en las historias de vida de los individuos, en las representaciones de sí mismos” ( $p$. 157), a lo que cabe agregar una profundización en sus concepciones de vida y de lo sucedido, interiorizando los eventos vivenciados, experimentados y lo que esto en palabra propia puede llegar a representar. Así, la vivencia oral como recurso metodológico, procura ampliar las fuentes utilizadas, además de la reivindicación con la memoria y un resurgir del silencio que ha marginado en distintas épocas y personas. Así pues, siguiendo a Jaramillo (2010) ve como "las fuentes orales parecen permitir una mayor comprensión de hechos traumáticos, de guerra y opresiones”. (p.65) Se intenta plasmar aquellos sucesos como historia valida; las cuales invita a reflexionar las diversificadas historias que se guardan, algunas para siempre sin tan siquiera poder ser contadas. De esta forma, las fuentes orales posibilitan una comprensión más amplia de sucesos hostiles y traumáticos sin perder de vista la caída del cerco de la victimización.

\section{1. Ser víctima de mina antiper- sona:}

Yo recuerdo que nos hostigaron unos cuatro o cinco y salimos a la persecución, el llamado señuelo y ellos nos tenían iun campo preparado!, una emboscada. Eso nos disparaban de todos lados, yo me fui a resguardar del fuego nutrido que tenían contra nosotros, yo me resguardé detrás de un árbol grande, frondoso, icon tan mala suerte que había instalada una mina y me levantó! Nunca perdí el sentido, me fui a parar y a buscar el fusil porque la explosión me lo quitó de las manos, mandé el paso y ni me había dado cuenta que había perdido el pie y me fui de cara como si hubiera pisado un hueco, fue cuando me di cuenta de lo de la pata, empecé a gritar, ahí sentí el dolor más hijueputa e indescriptible; yo solo buscaba mi fusil, era tanto el dolor, que de verdad pensé en dispararme en la cabeza, quería matarme, 
aunque no me lo dieron; yo decía, es la única forma de parar ese dolor.

Eso de todos lados nos disparaban, incluso varios se veían muy pelaos (jóvenes), eso los más experimentados casi siempre peleaban de último, cuando la tropa estaba ya desgastada, sin moral y sin munición. Me acuerdo de un pelaito, eso su camiseta le llegaba hasta las rodillas y así, corriendo con el fusil en el hombro y todo, disparaba hacia atrás con un miedo, de resto, eso se veía mover las ramas de donde disparaban apenas, imuy áspero! Ya en el suelo y viendo sangre, de pronto sentí un tirón duro, fue cuando apareció un compañero, me cogió del chaleco y me arrastró hacia atrás, donde estaban atendiendo más heridos. Yo recuerdo que la mano derecha me ardía mucho, se veía toda quemada y las esquirlas de la mina hicieron que saliera sangre como de todas partes del cuerpo, desde que la pisé, sentí un chillido profundo en el oído izquierdo, de hecho eso hizo que perdiera audición en ese oído. El enfermero nunca dejó de hablarme, siempre me preguntaron cosas y me decían: "Guebòn estás aquí con nosotros, no vayas a cerrar los ojos". Cuando ya me estabilizaron y la hemorragia como que paró, yo solo les pedía agua, era una sed infernal, imucha sed!...; me tocó resignarme con copos de algodón humedecidos de agua, porque fue lo único que me dieron para la sed. La hora en que caí, fue como a las 5: 30 de la tarde más o menos -imagínense-. iEso ya estaba todo oscuro! Y la evacuación ohm mejor dicho.... Para la evacuación, fue toda una odisea, porque no había helipuerto, les tocó hacer uno improvisado, eso tocó a las oscuras mochar arboles de todo lado para poder despejar; incluso el helicóptero nunca pudo aterrizar, ya que los troncos que mocharon quedaron muy altos, e impedían el aterrizaje, y es que antes, en plena oscuridad. Eso obligó a que hiciera el helicóptero vuelo estacionario y ahí sí, bajar una camilla en lazo y empezar a subir heridos. La extracción de todos los heridos incluyéndome, fue como a las 5:00 de la mañana. Esa noche fue infernal, yo solo escuchaba que eso eran sombreros chinos y que minas antipersona habían varias también, "era un campo preparado" pues.

Ese día en que yo caí, Tapidies un soldado, cayó por esquirlas en los ojos, perdió una vista; un cabo también, herido por arma de fuego en el abdomen y pierna, y pues, yo también sin una pierna y con heridas por todo lado. Como a la hora de yo haber caído, más o menos, llegó el avión fantasma y la arpía a apoyarnos y fue cuando los hicieron replegar. La contraguerrilla de nosotros era de 24 hombres, ellos eran 
como 120 -no entiendo hasta ahora por que no nos mataron, pudo haber sido peor- eso es un recuerdo que estará conmigo para siempre. En fin, ya ahí para delante fue duro, la primera atención que me dieron, fue el enfermero de combate y luego en el helicóptero, los paramédicos me daban mucha moral, tanto en tierra como en aire.

Recuerdo que mi última visita a la casa, fue en 2004, unas vacaciones, fueron como 15 días nada más antes de empezar la operación. Con los compañeros hubo una fiesta, eso fue de comida, trago, de todo mejor dicho isevero rumbom!, era como la forma de darnos moral antes de entrar a la operación; porque eso de la zona se escuchaba que era zona roja, y que en cuestión de horas se reagrupaban, se unían, Farc y ELN para enfrentarse con el Ejército o con los paras, "los primos" que llamábamos, nosotros nos comunicábamos con ellos y si estaban cerca eso de una llegaban a apoyarnos y viceversa, eso dependía. En septiembre de 2004, fue ya la fecha en la que partimos, el helicóptero nos llevó hasta cierto punto y luego infiltración. En el lugar, no íbamos a estar más de 15 días, según altos mandos, era golpear al enemigo y salir. Eso desde el helicóptero se veía un paisaje muy montañoso, solo montañas, casas casi no habían; sólo corredores de movilidad de la guerrilla. Eso a las cuatro de la tarde ya se oscurecía por lo tupido de la montaña y la neblina todo el día dejaba los arboles empapados, era como si hubiera llovido, aunque no. Eso es muy difícil, porque piensa uno que se va a morir y sin ni siquiera despedirse de nadie, quien iba pensar que de ahí iba a salir con eso, el cambio fue iáspero!...

La ciudad donde tuve la recuperación, eso se dio en... Bucaramanga, el tiempo fue como un mes internado, más el año y medio de tratamiento ambulatorio. De la recuperación se encargaron doctores, ortopedistas, enfermeras, psicólogos y terapeutas, eso sí estuvo sin falla. La terapia de adaptación fue muy fuerte, ya que esa pata, la prótesis pues, pesa y es un objeto extraño en el cuerpo, le toca a uno aprender a caminar otra vez y es algo muy doloroso y jodido, ya que el cuerpo rechaza extensiones que le ponen a uno, además que el muñón queda muy delicado e inflamado, entonces eso causa mucho dolor no más el verme todo amputado ya dolía.

Yo le decía a mi mamá: ivenga, venga, rásqueme ahí! - ¿dónde? - "ahí en mi tobillo izquierdo"...hijo ese fue el pie que le voló la mina, ¿cómo que rasque, 
si ya no lo tiene?, no sé pero me rasca demasiado $^{4}$, - le decía -

Yo recuerdo, que hubo una persona que me ayudó mucho en la recuperación, una joven jefe de enfermería, para mí, fue mucha la moral, ya que me dio un apoyo psicológico muy muy importante. Además que el lugar de recuperación, en sí no es muy agradable que digamos, entraban unos heridos, salían otros y así...eso es un hospital al fin de cuentas, todos los días estaban llegando gente herida. Las secuelas de la guerra van plasmadas en un país que les toca llevarlas a cuestas cada día.

\section{REFLEXIONES FINALES}

Evitando el discurso oficial acerca de los afectados de MAP, que los tildan de héroes o antihéroes; es importante mirar el sintomático cultivo de la guerra como componente cultural de la nación, siendo que los hechos violentos toman una naturalización que no pareciera generar mayor preocupación, en casos alarmantes, incluso pareciera haber generado mayor atención fuera de la nación que dentro, el dicho popular "nos matamos entre nosotros mismos" no pareciera ser tan distante de la realidad. Así, las historias generacionales cambian de acto-

${ }^{4} \mathrm{Al}$ que puede sumarse la manifestación sensorial de tener un miembro fantasma, que afecta res, aunque la dinámica empobrecedora y violenta, que permea y se mantiene en los escenarios agrícolas y citadinos de estas ciudades no cambia del todo. El caso de Ramiro, deja como reflexión que, el accionar un artefacto explosivo, es degradante social e individualmente sin importar que el implicado fuese campesino, civil o héroe, lo que los agrupa es el dolor y recuerdo que ha marcado la cotidianidad cultural de la guerra como forma de vida. Asimismo, el suceso de guerra narrado, afirma el apoyo de grupos paraestatales con los ejércitos regulares del Estado, que se configuró como el componente de una serie de desapariciones forzadas hasta los cuestionados falsos positivos. Así pues, los señalamientos oficiales de héroe o criminal no convergen a un llamado fundamental; el de la no degradación, afectación o pérdida de vidas si, de lo contrario, se estaría violando un principio de humanidad y libre desarrollo corporal y psicosocial.

Urge la importancia de lo local, de la reconstrucción en sí, rescatar lo dicho de los discursos populares no emergidos, lograr manifestar discursos e historias no oficiales; lo anterior adquiere verdadero sentido (metodológico), cuando fuentes orales obtienen un conocimiento particular que tiene Defensoría del pueblo (p. 7). 
relación íntima con parte de lo que se puede determinar historia de las victimas nacionales, ya que posibilitan restaurar la importancia de los cuerpos sociales, siendo personas conocedoras de experiencias indicadas y directas que tienen una historia en el tiempo. Aunque dichas historias pareciera enmarañarse y quedar ocultos en mentes olvidadas, se invita a revertir dicho fenómeno, logrando más posibilidad de dar voz a una historia en mente viva de los sucesos de guerra.

Se evidencia también que los esfuerzos sumados estatales han tenido mayor relevancia en los últimos años, cuya secretaria técnica ha asumido el departamento administrativo de presidencia de la república, por ejemplo, con la unidad de atención integral a víctimas, no obstante y como lo reconoce el Estado a través de la defensoría del pueblo (s.f), las victimas relacionadas con: bienestar y entorno "el temor por la nueva condición que puede tornarse crónico, la destrucción de su proyecto de vida, el trauma psicológico, la pérdida de capacidades físicas, el duelo que debe asumirse en relación con la pérdida y la ruptura del tejido social” (p. 7). Existen pues una serie de factores que determinan los posibles temores que desencadenan la recuperación parcial producto de artefactos explosivos.
En la reunión de los Estados parte de la convención de Ottawa, desarrollado en Viena (18 de diciembre de 2017) el director de Descontamina Colombia habla de avances favorables ya que hay 180 municipios libres de minas antipersonal, además de continuar con operaciones de desminado en más 242 municipios de 20 departamentos entre ellos Antioquia, meta, Caldas, Caquetá. Según su director dicha entidad, se han tomado medidas "Para adelantar tareas de desminado, la capacidad operativa del sector aumentó de 1.650 personas en junio de 2016 a cerca de seis mil personas en octubre de 2017. Todos estos hombres y mujeres están debidamente acreditados para realizar labores de despeje".

En otro momento, se debe tomar en serio si los afectados no encuentran un estilo de vida muy prospero e incluso si existe sentimiento de rechazo por parte de la comunidad donde se encuentran o temor y vergüenza por la transformación de su cuerpo, debido a que como expone Goffman (1993) "la vergüenza se convierte en una posibilidad central, que se origina cuando el individuo percibe uno de sus atributos como una posesión impura de la que fácilmente puede imaginarse exento" (p. 18). Esto hace que los inicios de recuperación sean profundamente melancólicos o depresivos para las personas que deciden enfrentar esta etapa, 
como también, "carente de saludable retroalimentación (feed-back) del intercambio social cotidiano con los demás, la persona que se aísla puede volverse desconfiada, depresiva, hostil, ansiosa y aturdida" (p. 24).

\section{A MODO DE COLOFÓN}

Por ser Colombia un país de sectarismos, polarización y antipatía política, se supone que hay muertes que duelen más que otras, -eso depende- sin reconocer que las pérdidas humanas por MAP y MUSE, debería dejar de tener mayor heroísmo y respeto si quien la pisó fue un activo de la fuerza pública y no un campesino, mujer, niño o incluso un insurgente que de alguna manera pudo haber sido víctima de su invento. Se intentó mostrar la naturalización de la muerte violenta como un caso que se sintiera hasta culturalmente cotidiano, de allí las líneas que mencionan la violencia cultural o la violencia como parte de la cultura Nacional. Aunque reacciones estatales no debieron darse de una forma tan parsimoniosa -respecto a las MAP, fenómeno existente en el Estado Colombiano mucho antes de hacer parte de la Convención de Ottawa, como país firmante, las mejoras en intervención de campos contaminados han avanzado. Ahora, en época de desarme a grupos históricos caso
FARC-EP, ha existido resistencia al cambio, es decir la fuerza por seguir en guerra no es menor, siendo que son varios los grupos que persisten en la violencia como forma de vida, de ahí que no conciban un país sin confrontación armada. Así pues, como diría Canclini sobre el aspecto cultural, "hay diversas maneras de concebir los vínculos entre cultura y sociedad, realidad y representación, acciones y símbolos" (CLACSO, 2001. P. 57). Los aspectos culturales que logran determinar al colombiano son una hibridación amplísima y esto en parte por la multiculturalidad regional desde épocas de la colonia, no obstante, no dejaría de ser la guerra, una de las configuraciones de la identidad nacional desde décadas.

El estado colombiano ha reconocido la alarmante problemática salida de las manos, tanto así que para los diez primeros años previstos para un desminado completo -según convenio internacional-, no fue suficiente, viendo la obligación de prórroga de más años. Fue notorio en épocas de mayor crisis, una carencia de integración socioeconómica hacia las personas afectadas y sobre todo de quienes en el momento del incidente no contaron con los beneficios dignos que por lo menos si tuvieron los hombres de la fuerza pública. Asimismo, es de vital importancia una pedagogía anti-MAP, en la que 
se eduque a comunidades directamente, siendo que es inimaginable lo problemático que resulta vivir día a día con la hostilidad de los artefactos explosivos en parcelas de tierra de subsistencia campesina; aunque lo anterior ha sido uno de los referentes de los programas estatales con los modelos de intervención a comunidades, no han sido suficientes.

Agradecimientos

A Ramiro, por su confianza y tranquilidad al abrir las puertas de los recuerdos no gratos de su vida. El escuchar su historia, muestra sólo uno de cientos de casos de valentía y obstinación por seguir adelante pese a las inesperadas dificultades que un país de hostilidad como Colombia ofrece a sus ciudadanos.

\section{REFERENCIAS BIBLIOGRÁFICAS}

Canclini, N. (1981). Cultura y Sociedad: Una introducción. Mexico D. F.: Dirección General de Educación Indígena de la SEP.

Comité Internacional de la Cruz Roja. (1998). Prohibición de las minas antipersonal y sobre su destrucción. Tratado de Ottwa. Ginebra, Suiza .

Congreso de la Republica. (10 de Junio de 2011). LEY 1448 DE 2011 (Junio 10) Por la cual se dictan medi- das de atención, asistencia y reparación integral a las víctimas del conflicto armado interno y se dictan otras disposiciones. Bogotà D.C., Cundinamarca, Colombia.

Convención sobre la prohibición del empleo, almacenamiento, producción y transferencia de minas antipersonal y sobre su destrucción. (1997). Convención de Ottawa, (pág. 15). Ottawa, Canadá.

Defensoria del pueblo. (s.f). Orientacion psicojuridica a victimas de minas antipersonal y municiones sin explotar. Bogotà D.C.: Imprenta Nacional de Colombia.

Díaz, G. (2003). Minas antipersonales (M.A.) en Colombia costo físico y emocional. Umbral Científico, 2-7.

Dirección para la acción integral contra minas antipersonal. Descontamina Colombia. (31 de octubre de 2017). Víctimas de Minas Antipersonal y Municiones sin Explosionar Recuperado de: http://www.accioncontraminas.gov.co/estadisticas/Paginas/victimas-minas-antipersonal.aspx

Documento Conpes. Consejo Nacional de Politica Economica y Social. (2009). En Politica Nacio- 
nal de acción integral contra minas antipersonal (MAP), Municiones sin explotar (MUSE) y artefactos explosivos improvisados (AEI) (págs. 15-16). Bogotá D.C.

Galtung, J. (2003). Violencia Cultural. Gernika Gogoratuz, 1- 36.

Gamboa, A. (2013). Experiencia de violencia y restitución en sobrevivientes de minas antipersonales en el Magdalena medio Colombiano. Revista Colombiana de Antropologia. Vol. 49, 153-176.

Goffman, E. (1963). Estigma. La identidad deteriorada. Buenos Aires: Amorrortu editores.

Jaramillo, P. (2010). Ejércitos iregulares y organizaciòn campesina: Guàimaro, el camino hacia la restituciòn del derecho a la tierra. Revista Colombiana de Sociologìa, 63-80.

Mato, D. (2001). Introducción Estudios latinoamericanos sobre cultura y transformaciones sociales en tiempos de globalizacion. En: Estudios latinoamericanos sobre cultura y transformaciones sociales en tiempos de globalizacion (pp 13-29) Buenos Aires: Consejo Latinoamericano de Ciencias Sociales (CLACSO)

Politica nacional de acciòn integral contra minas antipersonal. (9 de
Octubre de 2008). Obtenido de http://www.accioncontraminas.gov.co/Documents/Politica_Nacional_Accion_Integral_contra_Minas_Antipersonal.pdf

Presidencia de la República. (2014). Programa presidencial para la acción contra las minas antipersonas. PAICMA. Bogotá D. C.: Imprenta nacional de Colombia.

Procuraduría Delegada para la prevención en materia de derechos humanos y asuntos étnicos, Grupo de Justicia Transicional. (2011). Dirección para la acciòn integral contra minas antipersonal. Descontamina Recuperado de: http://www.accioncontraminas.gov.co/accion/desminado/planeacion/documento_procuraduria.pdf

Programa de Acción Integral Contra Minas Antipersonal (PAICMA) 2014. (pp. 114-115).

Recuperado de: http://www.accioncontraminas.gov.co/prensa/Documents/Normatividad\%20AICMA\%202014.pdf" http://www.accioncontraminas.gov.co/prensa/Documents/Normatividad\%20AICMA\%202014.pdf 
Unicef. (Septiembre de 2000). Colombia y las Minas Antipersonal. Sembrando Minas cosechando muerte. Obtenido de https://www.unicef.org: https://www.unicef.org

Viceprecidencia República de Colombia. (2008). Programa Presidencial para la Acción Integral contra Minas Antipersonas. Bogota D.C.

\section{PARA CITAR ESTE ARTÍCULO:}

Oviedo, C. (2017). Mirada reflexiva de las minas antipersonal (MAP); municiones sin explotar (MUSE) y artefactos explosivos improvisados (AEI) en Colombia. Acercamiento desde el análisis de caso. Collectivus, Revista de Ciencias Sociales, 4(2), 5577.

DOI: http://dx.doi.org/10.15648/Coll.2.2017.4

Recibido: 17/02/2017 Aprobado: 21/05/2017 